Accepted refereed manuscript of: Cage E, De Andres M \& Mahoney P (2020) Understanding the factors that affect university completion for autistic people. Research in Autism Spectrum Disorders, 72, Art. No.: 101519. DOI: https://doi.org/10.1016/j.rasd.2020.101519

(C) 2020, Elsevier. Licensed under the Creative Commons Attribution-NonCommercial-NoDerivatives 4.0

International http://creativecommons.org/licenses/by-nc-nd/4.0/

\title{
Understanding the factors that affect university completion for
}

\section{autistic people}

\author{
Eilidh Cage $^{1,2}$, Maria De Andres ${ }^{1} \&$ Paige Mahoney $^{1}$ \\ ${ }^{1}$ Department of Psychology, Royal Holloway, University of London, Egham, Surrey, UK, TW20 0EX \\ 2Present address: School of Psychology, University of Stirling, Stirling, UK, FK9 4LA
}

Corresponding author: Eilidh Cage, eilidh.cage@stir.ac.uk

Manuscript accepted for publication in Research in Autism Spectrum Disorders on 27/1/2020 


\begin{abstract}
Background: Autistic individuals may be less likely to complete their university studies, but there is no research to date that examines why this is the case. This study thus examined the factors that may affect university completion for autistic people.

Method: Two-hundred and thirty autistic people who had attended university completed an online survey, whereby 151 had graduated on their first attempt, 34 graduated after several attempts, and 45 had not completed. Participants answered questions regarding the transition to university, academic and social experiences, diagnosis, mental wellbeing and sensory sensitivities.

Results: Those who did not complete had a poorer academic experience, found the transition more difficult, and felt less organisational and social identification at university. Logistic regression suggested the transition to university is particularly important in predicting non-completion.

Conclusions: Finding the transition challenging and struggling with academic and social aspects may contribute to the risk of dropping-out. The study has implications for universities, who must ensure all autistic students are able to achieve their full academic potential by providing appropriate transition support, fostering a sense of community at university and ensuring staff are appropriately trained.
\end{abstract}

Key words: Higher education; autistic students; non-completion; dropout 
In 2017/18 there were 11,015 autistic ${ }^{1}$ students recorded in the UK (HESA, 2019). Research to-date discusses how autistic students can be supported to achieve their potential (e.g. Chown, BakerRogers, Hughes, Cossburn \& Byrne, 2017; Gelbar, Shefcyk \& Reichow, 2015; Gelbar, Reichow \& Shefcyk, 2014; Jansen, Petry, Ceulemans, Noens \& Baeyens, 2016; Thompson, Bolte, Falkmer \& Girdler, 2018). However, many autistic individuals do not complete their studies, and may be less likely to do so than non-autistic peers (Anderson, Carter \& Stephenson, 2017), yet little is known about why this may be the case. The current study aimed to examine the experiences of autistic people who had not completed university, in comparison to those who had, to develop a nuanced understanding of the factors that may affect completion.

Although autistic individuals have varying support needs, many can succeed in Higher Education (HE). Strengths such as passion about a topic, attention to detail and analytical skills can be highly beneficial (Barnhill, 2014; Gobbo \& Shmulsky, 2014; Van Hees, Moyson \& Roeyers, 2015). University can present many opportunities, although it is not without challenges (Robertson \& Ne'eman, 2008), such as difficulties with social interactions, sensory sensitivities and mental health comorbidity (Gobbo \& Shmulsky, 2014; Knott \& Taylor, 2014; Van Hees et al., 2015). It is unknown how these strengths and challenges might influence completion rates.

Previous research has identified factors that affect whether non-autistic students complete university, including experiences of pre-university education, feeling isolated, lack of social support and poor course choice (Christie, Munro \& Fisher, 2004; Harrison, 2006; Smith \& Naylor, 2001). For students with ADHD, learning disabilities or mental health conditions, Wolf (2001) speculated that noncompletion is affected by personal factors, such as self-esteem, social skills and difficulties with executive functions. For Canadian disabled students, Duquette (2000) noted that successful academic integration, rather than social integration, played an important role in completion. Currently, there is no research on this topic for autistic students. The current study thus explored a range of factors that could influence completion for autistic students.

\section{Proposed factors relating to non-completion}

\footnotetext{
${ }^{1}$ We use identity-first language in this article to reflect the preferences of the UK autism community (Kenny et al., 2016).
} 
First, it has been suggested that the transition to university can be particularly challenging for autistic individuals (Toor, Hanley \& Hebron, 2016). Coming to university involves familiarisation with new environments, independence and routines - aspects which some autistic people could find challenging (White, Ollendick \& Bray, 2011). Some autistic students report feeling like the transition is a 'gigantic leap' (Bolourian, Zeedyk \& Blacher, 2018). If the transition experience is particularly negative, this could impact on an autistic individual's decisions around continuing their studies.

Once at university, autistic individuals must decide whether to disclose their autism diagnosis. Many experience anxiety or choose not to disclose (Beardon \& Edmonds, 2007; Knott \& Taylor, 2014), feeling uncomfortable about being labelled as autistic (Van Hees et al., 2015), partly due to concerns over stigmatisation (Morris, 2011). Conversely, in MacLeod, Allan, Lewis and Robertson's (2018) qualitative study, autistic students described becoming 'extra visible' to fight against stereotypes at university. However, diagnosis may not occur until after the individual has started or left university, especially for autistic females (Loomes, Hull \& Mandy, 2017). The point at which diagnosis occurred, and whether this diagnosis was disclosed, may relate to non-completion. If autistic students are diagnosed and do disclose, they can access accommodations (Jansen et al., 2016) such as extra time in exams, regular meetings with a Disability Service staff member and/or a specialist mentor (Gelbar et al., 2015). A lack of appropriate support could relate to non-completion.

This lack of support could impact on the challenges experienced while studying. Some autistic students may find aspects of teaching and evaluation difficult, such as issues with processing large amounts of information in lectures or becoming waylaid by details (Jansen et al., 2016). Some teaching methods - such as a proclivity towards group work - could be a source of stress (Jansen et al., 2016), although some may enjoy group work (Wiorkowski, 2015). Challenging academic experiences, and a lack of support to overcome these, could contribute to a growing sense of dissatisfaction and desire to drop-out.

Further, research examining autistic student's experiences of HE highlights social interactions as a specific challenge (Gurbuz, Hanley \& Riby, 2019; Longtin, 2015; Knott \& Taylor, 2014; Madriaga \& Goodley, 2010). As well as opportunities to develop friendships with course-mates, autistic students may have to navigate relationships within student accommodation (Knott \& Taylor, 2014). Social difficulties could contribute to feelings of loneliness, a lack of identification with the university 
(organisational identity) or little identification with other students (social identification). Although social difficulties relate to the characteristics of autism, this does not mean social desire is absent (Cresswell, Hinch \& Cage, 2019). Feeling lonely, like one does not belong or part of the community of students could relate to non-completion.

In addition, around $80 \%$ of autistic people experience mental health conditions (Lever \& Geurts, 2016), therefore this may be an important factor affecting experiences at university (Anderson et al., 2017), as well as interacting with the factors outlined above. Mental health issues can influence academic performance (Gelbar et al., 2015; Van Hees et al., 2015), impact on everyday tasks (Knott \& Taylor, 2014) and interfere with the ability to learn (Gobbo \& Shmulsky, 2014). In Ward and Webster's (2017) interview study, they noted that even for autistic students succeeding in HE, anxiety and depression affected successful outcomes. Mental health comorbidity could increase the likelihood of non-completion.

Further, sensory sensitivities could contribute to stress and anxiety, cause difficulties with socialisation and prevent autistic students from focusing on academic work (Anderson et al., 2017). Autistic individuals have sensory sensitivities meaning they can be hyper- or hypo-sensitive to different sounds, textures or sights (APA, 2013). These sensory sensitivities can affect university life due to the risk of sensory overload, meaning the individual is not able to function within that environment (Gurbuz et al., 2019; Van Hees at al., 2015). Academic staff are thought to be less aware of this aspect of autism (Knott \& Taylor, 2014) therefore accommodations may be lacking. It may be that those who do not complete find the sensory environment at university too overwhelming.

Overall, the current study aimed to examine how the outlined factors - the transition to university, diagnosis and disclosure, academic experiences, social experiences, mental health and sensory sensitivities - might differ depending on university completion. This study is exploratory, given the lack of research on the topic, with the research question of 'which factors contribute to university completion for autistic people?' Online survey methodology was utilised to enable exploration of these factors in a wide range of autistic people. Both those who had completed university and those who had not were recruited to allow comparisons between groups. 


\section{Methods}

\section{Participants}

Overall, 230 autistic people took part in an online survey. Participants were recruited via advertisements on social media, autism-related groups or charities, university disability services and word-of-mouth. Recruitment took place between March and August 2018. There were 71 males (30.0\%), 144 females (60.8\%), 19 who identified with other genders $(8.0 \%)$ and three who preferred not to say $(1.3 \%)$. The mean age was $33.90(S D=10.28)$ and most participants were White British $(61.3 \%)$ or other White backgrounds (25.2\%), with others identifying with mixed ethnicities $(5.2 \%)$, Asian (2.6\%), 'other' ethnicities (2.2\%) or preferred not to say (1.3\%).

Most (47.4\%) reported a diagnosis of Asperger's Syndrome or an Autism Spectrum Condition diagnosis (42.6\%, overlap due to participants selecting more than one option), $1.3 \%$ reported Pervasive Developmental Disorder Not Otherwise Specified (PDD-NOS) and 20.9\% reported selfdiagnoses. Mean age of diagnosis was 28.87 ( $S D=11.96)$. All participants scored above the cut-off of 14 on the RAADS-14 (Erikson et al., 2014, $M=32.94, S D=6.73$ ), thus those who were self-diagnosed were retained in the sample. $81.3 \%$ of participants reported mental health diagnoses, most commonly depression (58.7\%), generalized anxiety disorder (38.3\%) and social anxiety (30.0\%).

Ethical standards were in accordance with the Declaration of Helsinki and ethical approval was obtained from Royal Holloway, University of London. All participants gave full informed consent before participating.

University demographics. Participants had studied STEM subjects (54.7\%), humanities (29.6\%), business or law $(10.8 \%)$ or creative arts $(7.8 \%)$. The majority had studied in the 2010 s $(50 \%)$ or 2000 s $(26.5 \%)$. Most completed their studies in the UK (64.3\%) with others most often studying in the United States or Canada (18.7\%) or other European countries (10.5\%).

Participants were grouped according to completion status - those who graduated on their first attempt (hereafter 'graduated', $n=151)$, graduated after several attempts $(n=34)$ or did not complete $(n=$ 45). Those who had graduated after several attempts were considered a separate group as they may have had unique experiences after leaving and returning to HE. On average, they had made two attempts before graduating. For the non-completion group, 35.6\% had left their studies during or just 
after the first year, $26.7 \%$ during or just after their second year and $22.2 \%$ during or just after their third or fourth year. Six participants reported leaving at different time points following several attempts at studying.

Although there were no significant differences between groups in terms of age $(p=.76)$ or country of study $(p=.98)$, there was a difference in gender $(X(4)=10.24, p=.037)$, with proportionally more males in the non-completion group (50\% male, $43.2 \%$ female, $6.8 \%$ other) than in the other groups, where there were more females (graduated: $26.7 \%$ male, $64.7 \%$ female, $7.3 \%$ other, $1.3 \%$ prefer not to say; graduated after several attempts: $21.2 \%$ male, $69.7 \%$ female, $9.1 \%$ other).

\section{Materials and procedure}

Participants completed the survey online, presented using 'Qualtrics'. Questions were presented in the order discussed below.

University demographics. Participants completed questions about their studies including where, what and when they had studied and whether they had graduated. They selected from a list of possible reasons why they had chosen their course and university. They also specified where they had lived in first year.

Academic experiences. Participants rated 13 statements pertaining to academic experiences, such as "I enjoyed most lectures on my course". Each statement was rated on a 5-point Likert scale (strongly disagree (1) to strongly agree (5)). Items were summed, with higher scores indicating a better academic experience. The items had very good internal consistency (Cronbach's $\alpha=.84$ ).

Social experiences. Participants completed measures examining organisational identity (feeling part of the university) and social identification (fitting in with other students; Wilkins, Butt, Kratochvil \& Balakrishnan, 2016). Four items measured organisational identification (e.g. "I felt a strong sense of belonging with my university", $\alpha=.91$ ) and five items measured social identification (e.g. "I felt a connection with the other students in my degree programme", $\alpha=.91$ ) with items rated on a five-point scale (strongly disagree (1) to strongly agree (5)). Participants completed the three-item UCLA Loneliness Scale (Hughes et al., 2004) phrased to prompt participants to think about their time at university (e.g. "When you were at university, how often did you feel isolated?"). These items were 
rated on a three-point scale ('hardly ever' (1) to 'often' (3); $\alpha=.90$ ). Finally, they were presented with an open question to input "anything else [you would like to tell us] about your social experiences whilst at university".

Support at university. Participants selected if they had received support for their needs as an autistic individual, mental health needs, physical health needs or if they had not received support or had asked for support but not received it. Those who had received support selected what type of support they had received (e.g. mentoring, note-taking). All participants were asked an open question of "what support would you have liked to have been provided?"

Diagnosis and disclosure. Participants selected their specific diagnosis, whether they had received their diagnosis before, during or after university and age at diagnosis. If participants received their diagnosis before or during university, they were asked whether they had disclosed to their university. All participants also reported mental health diagnoses.

The transition to university. Participants answered how easy they had found going to university on a five-point scale ('extremely easy' (1) to 'extremely difficult' (5)). Participants then rated nine items (from 'strongly disagree' (1) to 'strongly agree' (5)) pertaining to their transition experience (e.g. "I was worried about coming to university"). Participants could select if items were not applicable (e.g. "my friends supported me when I came to university"). A mean score was used since there were nonapplicable items for some participants. A higher mean indicated a more positive transition experience $(\alpha=.73)$.

Mental health. The Warwick-Edinburgh Mental Wellbeing Scale (Tennant et al., 2007) was phrased in the past tense to prompt participants to think about their time at university (e.g. "I felt optimistic about the future"). Participants rated 14 items on a five-point scale ('none of the time' (1) to 'all of the time' (5)). Internal consistency was very good $(\alpha=.89)$.

Autistic characteristics. Participants completed the Ritvo Autism and Aspergers Diagnostic Scale (RAADS, Erikson et al., 2014). This measure screens for autistic characteristics and includes 14 items (e.g. "I often don't know how to act in social situations") rated on a 4-point scale ('true now and when I was young" (3) to "never true" (0)). The RAADS was used to validate self-reported autism diagnoses. Three items corresponding to sensory sensitivities (e.g. "when I feel overwhelmed by my senses, I 
have to isolate myself to shut them down") were summed to create a sensory sub-total. Internal consistency was good $(\alpha=.72)$.

Finally, participants completed demographic information such as their age, gender identity, and ethnicity. The survey took approximately 17 minutes to complete.

\section{Design and data analysis}

This study had a cross-sectional survey design. The study was exploratory, examining how different factors may relate to completion. The survey was designed following reviewing of the literature and consultation with two autistic adults who had experience of not completing their studies. They reviewed a draft survey in full and offered feedback that was incorporated into the final survey, such as the wording of questions and additional relevant items.

Statistical analyses examined differences between groups (graduated, graduated after several attempts, did not complete). Initial analyses tested for differences according to country of study (UK or non-UK), however no differences were found and country was not included as a variable of interest in the final analyses. Non-parametric tests are reported where data were not normally distributed. Since there were different proportions of males and females in the groups, gender was controlled for where possible.

After testing for group differences for each factor, logistic regression examined which factor(s) might be the best predictor of completion. Here, participants from the non-completion group were matched to participants who had graduated on age, gender and country. This resulted in 40 participants who did not complete matched to 40 participants who had graduated on their first attempt.

Qualitative questions regarding social experiences and support desired were analysed using conventional content analysis, which aims to identify categories that fit closely with the data (Hsieh \& Shannon, 2005). Two independent raters reviewed all responses and then met and agreed categories, before coding responses into the categories. 


\section{Results}

\section{Experiences of the transition to university}

Kruskal-Wallis found a significant difference between groups in how easy they found the transition to university $(H(2)=10.89, p=.004)$. Mann-Whitney tests were used to examine this finding, with a Bonferroni correction using a conservative $p$ value of .0167 . There was a significant difference between those who had graduated and those who did not complete ( $U=2410.5, p=.003, r=-.21)$, with those who did not complete finding the transition more difficult $(M d n=4)$ than those who graduated $(M d n=3)$. There was no significant difference between those who had graduated after several attempts $(M d n=4)$ compared to either group ( $p s>.043)$.

Between-subjects ANCOVA (controlling for gender) examined differences in mean transition experience score. Levene's was not significant $(F(2,224)=.34, p=.71)$. There was a significant main effect of group $\left(F(2,223)=3.38, p=.036, n p^{2}=.029\right)$. Post-hoc analyses indicated a significant difference between those who did not complete $(M=2.69, S D=.66)$ and those who graduated $(M=3.00$, $S D=.64, p=.031)$. There were no significant differences compared with those who graduated after several attempts $(\mathrm{M}=2.96, S D=.72, p s>.28)$.

\section{Diagnosis and disclosure}

Most participants were diagnosed after university: $60.3 \%$ of those who had graduated, $58.8 \%$ of those who graduated after several attempts and $57.8 \%$ of those who did not complete, with no significant association between group and timing of diagnosis $(X(4)=1.89, p=.76)$. There was no significant difference in age of diagnosis between groups $(F(2,195)=.17, p=.84)$. If diagnosed before or during university, $73.9 \%$ ( $n=34)$ of those who graduated disclosed to their university, and $84.6 \%$ of both those who graduated after several attempts $(n=11)$ and those who did not complete disclosed $(n=11$; $X(2)=1.36, p=.51)$.

\section{University experience: Course and university choice}

Participants selected the reasons why they had chosen their course and the university. Table 1 indicates overall similarities in why participants in the different groups picked their course and 
university, such as choosing the course due to interest in the subject and relationship to career plans, and choosing the university based on location and because of the specific course.

[Insert Table 1 here]

\section{Academic experiences}

Kruskal-Wallis test examined differences in academic experience score, finding this was significantly affected by group $(H(2)=16.20, p<.001)$. Mann-Whitney tests with Bonferroni correction (as above) found only a significant difference between those who had graduated and those who had not completed $(U=1975.50, p<.001, r=-.28)$, such that those who did not complete had a more negative academic experience $(M d n=40)$ than those who graduated $(M d n=47)$. There were no differences compared to those who had graduated after several attempts $(M d n=45.5)$.

\section{Support at university}

Table 2 shows whether participants had received support for their needs while at university, with most receiving no support, and there was no association between group and whether they had received support for each need. However, there were associations with timing of participants' autism diagnosis and support received, such that those who were not diagnosed until after university were less likely to receive support (Table 2). For those who had received support, most often they had received counselling ( $n=55)$, extra time in exams $(n=51)$ or Disabled Students Allowance $(n=34)$.

[Insert Table 2 here]

Qualitative data on the support participants would have liked was analysed using content analysis. 141 participants provided responses and the analysis was conducted within each group. Categories and example quotes are shown in Table 3. For those who did not complete $(n=24)$, four categories were identified: "academic support" was the most common, characterised by participants indicating they would have appreciated more support in organising their studies or accessing help for assessments. "Autism awareness" referred to participants desiring peers and staff were more aware of autism, but also wishing they themselves had been aware that they were autistic at the time, since they were not diagnosed until after university. "Counselling" identified how participants believed they would have benefitted from a counsellor to discuss mental health difficulties. Finally, "staff support" 
was uniquely identified as a category for this group, referring to participants wanting better quality support from university staff.

[Insert Table 3 here]

For the graduated group ( $n=93$ ), six categories were identified, with three overlapping categories with those who did not complete. The most common categories were "autism awareness", "academic support" and "counselling" as described above. These participants discussed three additional categories: "sensory support", which encompassed a wish for sensory friendly spaces on campus; "networking opportunities", a desire for opportunities to network with other autistic people, and "communication support", with participants desiring more opportunities to build social skills.

For those who graduated after several attempts $(n=24)$, five of the same categories were identified: "autism awareness" was the most commonly identified category, followed by "counselling" and "academic support". Less common categories were "sensory support" and "communication support".

\section{Social experiences}

Multivariate Analysis of Covariance (MANCOVA) examined group differences in organisational identification and social identification at university, controlling for gender. Box's Test of Equality of Covariance Matrices was not significant ( $p=.90)$. Pillai's Trace indicated a significant effect of group $(F(4,408)=4.85, p=.001)$. Subsequent one-way ANOVAs (Levene's not significant, $p s>.51)$ indicated significant differences between groups for organisational identification $(F(2,204)=7.54, p<.001$, $\left.\eta p^{2}=.069\right)$ and social identification $\left(F(2,204)=5.87, p=.003, n p^{2}=.054\right)$. Post-hoc analyses using Bonferroni indicated significant differences only between those who had graduated and those who did not complete for organisational identification $(p<.001)$ and social identification $(p=.007$; Figure 1$)$. For loneliness, Kruskal-Wallis indicated a significant difference between groups $(H(2)=6.30, p=.043)$. However, while subsequent Mann-Whitney tests indicated a difference between those who graduated and those who graduated after several attempts $(U=1996.00, p=.041, r=-.15)$, this was not significant at the corrected $p$ value $(.0167)$.

[Insert Figure 1 here] 
Qualitative data regarding social experiences at university was analysed using content analysis. 129 participants provided responses and the analysis was conducted within each group. Categories and example quotes are shown in Table 4. For those that did not complete $(n=16)$ two categories were identified: "Limited or superficial friendships" referred to a tendency towards creating shallow bonds rather than meaningful friendships or basing their social experiences on one individual. "Loneliness" was also identified, where participants reported feeling isolated and left out of social activities.

[Insert Table 4 here]

For the graduated group ( $n=90)$ six categories were identified. As above, "Ioneliness" was a common category. The category of "social difficulties" characterised participants' difficulties when interacting and understanding others despite being socially motivated. "Common and structured interests" was characterised by a tendency towards creating bonds with like-minded people typically within structured activities. Uniquely in the graduated group, two additional categories were identified: "lack of acceptance" encompassed participants feeling misunderstood and judged by others; and feeling "overwhelmed by student nightlife", a discomfort about activities revolving around alcohol consumption or parties.

For participants that graduated after several attempts $(n=23)$ four categories were identified, with "Ioneliness", "lack of acceptance" and "common and structured interests" referred to as above. A unique category of "distance" was also identified, with participants finding socialising difficult if they lived further away from university.

\section{Living situation}

Table 5 shows participants' living situation in the first year of study. Chi square examined the association between group and living situation, excluding those who had selected 'other'. This analysis indicated a significant association between group and living situation $(\chi(4)=11.38, p=.023)$. Post-hoc analyses using adjusted residuals and a Bonferroni corrected $p$-value of .0056 indicated that those who did not complete were more likely to have lived in private accommodation than expected (adjusted residual= 2.9, $p=.0037$ ).

[Insert Table 5 here] 


\section{Wellbeing at university}

Mean wellbeing was 39.16 ( $S D=10.67)$ for those who did not complete, $41.40(S D=9.62)$ for those who graduated and $38.88(S D=9.82)$ for those who graduated after several attempts. Betweensubjects ANCOVA (controlling for gender, Levene's not significant, $p>.80$ ) found no significant differences in wellbeing scores between groups, $F(2,223)=1.34, p=.27)$.

\section{Sensory sensitivities}

Median sensory score for those who did not complete was 7, for those who graduated was 8 and for those who graduated after several attempts 9 . Kruskal-Wallis test indicated no significant differences in sensory sensitivity between groups $(\mathrm{H}(2)=1.72, p=.42)$.

\section{Exploratory analysis: predicting completion}

Forty participants who did not complete were matched to 40 participants who had graduated (on their first attempt) on age, gender and country. Logistic regression was used with completion (graduated or did not complete) as the outcome, and ease of transition, transition experience, organisational identification, social identification, academic experience and living situation (dummy coded) entered as predictor variables. These variables had been identified as variables of interest within previous analyses, and the current analysis enabled exploration of which factor(s) might predict completion when controlling for variance explained by other variables.

The model was significantly better at predicting the outcome than the mean alone $\left(x^{2}(6)=23.57\right.$, $p=.001$ ) and $69.6 \%$ of cases could be classified correctly using the model. The only significant predictor in the model was the ease of transition, such that the more difficult they found the transition, the more likely they were to be in the non-completion group (Table 6).

[Insert Table 6 here] 


\section{Discussion}

The current study aimed to enhance understanding of the factors that contribute to university completion for autistic people. Difficulty with the transition to university was identified as a factor that may play an imperative role in the risk of non-completion. Other factors such as a lack of social and organisational identification may also contribute, with those who did complete feeling like they did not fit in and did not belong to their university. The academic experience at university was also poorer for this group, suggesting that difficulties with academic aspects may also contribute. Finally, it was noted that those who did not complete were more likely to have lived in private accommodation.

Finding the transition to university difficult may increase the likelihood of non-completion for several reasons. As Glennon (2001) notes, autism is a 'hidden' condition, therefore others' expectations may be based on a perception that the individual does not 'look' like they need support with the transition. Therefore, some may find themselves struggling early on at university but are met with an expectation that they should be coping. Autistic people may often find the transition to university difficult (Toor et al., 2016; White et al., 2011) and processing the unknowns the transition presents (Bolourian et al., 2018). If the transition is difficult, this could lead to the decision to leave university.

It must be noted that since most of the sample were late diagnosed, these participants may have found themselves struggling with the transition and lacking support for their needs, or being unaware that some of their challenges may relate to being autistic. Diagnosis is important so appropriate support can be utilised (Cai \& Richdale, 2016), and disclosure of diagnosis can be met positively by peers (Brosnan \& Mills, 2016) although it is a challenging issue to navigate (Cox et al., 2017). The current sample was mostly female, which may also explain why many were diagnosed later in life since autistic women are more likely to experience barriers to diagnosis (Loomes et al., 2017). The qualitative findings also support the notion that diagnosis pre-university would be beneficial, with participants (in all groups) wishing they had been aware they were autistic at university. Further, those who did not receive their diagnosis until after university were less likely to receive support, including for their mental health needs. This finding suggests that an autism diagnosis helps with accessing support of different forms, not just autism-specific support. Timing of diagnosis did not relate to the risk of non-completion but may be a general issue faced by autistic people accessing HE. 
Several other factors also differed between groups. Social and organisational identification at university - feeling part of the student community and belonging to the university - was lower in those who did not complete compared to those who graduated. Those who did not complete likely had fewer opportunities to develop social identification or may have had more social difficulties which impacted on fitting in. Those who graduated likely still had social difficulties (Cai \& Richdale, 2016) but may have nonetheless formed a sense of belonging. For example, university has been noted as offering social opportunity for autistic people, through finding like-minded others and offering structured social activities (Lei et al., 2018). In the current study, qualitative data also showed that those who did not complete uniquely described having limited or superficial friendships. Relying too much on one person or experiencing only shallow friendships could contribute to the lack of social and organisational identification.

Interestingly, there were no group differences in loneliness at university. This may reflect a ceiling effect whereby loneliness was high in all groups and higher than research with non-autistic people (e.g. Hughes et al., 2004; Luhmann \& Hawkley, 2016). Qualitative data also indicated loneliness was commonly experienced in all three groups. Loneliness may be experienced by many autistic adults who feel discrepancy between their social desire and this desire being met (Mazurek, 2013). Previous research has noted high feelings of loneliness at university for autistic students (Jackson, Hart, Brown \& Volkmar, 2018), therefore universities should aim to reduce these feelings for all autistic students. For example, universities could actively develop peer networks that enable autistic students to support one another, as well as ensuring student societies are accessible to help autistic students meet others with similar interests.

An added social complexity at university involves one's living situation, and this study found those who did not complete were more likely to have lived in private accommodation in their first year. While student halls may present social challenges with large, communal living spaces (Knott \& Taylor, 2014), halls may also enable easier access to support, which could help with the transition to university - for example, by offering access to residential support officers (Ackles, Fields \& Skinner, 2013) or being on-campus near to facilities (Cox et al., 2017). Hence this may partly explain why living in private accommodation could relate to non-completion, with reduced opportunities to access support or for concerns to be noticed by the university. 
Finally, those who did not complete reported a poorer academic experience than those who graduated. Finding the course uninteresting, lectures difficult to understand and being dissatisfied with grades are elements of the academic experience which could contribute to an increased desire to leave. This finding supports Duquette's (2000) claim that for disabled students academic integration is vital for completion. In the qualitative data, those who did not complete reported needing more academic support such as accessing help for assessments or organising their studies. This group also uniquely described issues with support from staff, feeling that staff were unapproachable or unable to help them.

Finally, it should be noted that the participants who graduated after several attempts did not differ to the other groups, positioning in between the two other groups. This finding makes sense given that this group had experience of dropping out then later graduating and justifies consideration of this group separately. Qualitative data indicated many similarities to those who had graduated on their first attempt. One unique category was identified centring around the impact of distance on their social experiences, whereby some described how they were typically not living on campus or commuting to university, and this impacted on their social experiences. It is important to acknowledge the unique pathways autistic people may have through HE.

\section{Limitations}

The sample is not representative for several reasons. First, participants participated on a voluntary basis with an interest in the research topic, lending to a biased sample. Second, the sample consisted of predominantly late-diagnosed people, with a high proportion of females. As many were not diagnosed until after university, this limits what this research can tell us about students diagnosed beforehand. Further, some of the sample were self-diagnosed (although scoring highly for autistic characteristics). These participants will not have qualified for any autism-specific support at university and it is unclear what diagnostic barriers may be preventing these participants from obtaining a diagnosis. The results must therefore be interpreted with caution in light of these sample limitations. However, pre-existing research has been conducted with current students who are diagnosed (e.g. Jackson et al., 2018; Jansen et al., 2016) therefore the current study adds to the literature by widening knowledge of HE experiences for a range of different autistic people. Some autistic people with lower support needs may not consider or realise the possibilities of an autism diagnosis until they 
are at, or after, university. It is likely that female participants had experienced several barriers that prevented them from accessing an autism diagnosis earlier in life (Loomes et al., 2017; Leedham, Thompson, Smith \& Freeth, 2019). Therefore the current study calls for better access to early diagnosis, to enable appropriate support to be in place throughout education.

There was also a small sample within the groups who did not complete and graduated after several attempts. The findings are treated with caution but offer a starting point given the dearth of research on non-completion for autistic people. The small sample also prohibits analysis of interactions between different factors, and it is unlikely that the factors operate in isolation. For example, it is unclear how difficulties with the transition may relate to social or academic challenges. Further, it was not possible to control for other variables such as type and location of university, family social and economic status, academic ability or the percentage of other autistic students at the university. Nonetheless, we hope the current study stimulates further research into this topic, including larger quantitative studies with appropriate controls (potentially using population surveys) and in-depth qualitative work.

Finally, the study did not directly compare to non-autistic students who have been unable to complete their studies. Past research with non-autistic individuals has highlighted how factors such as poor university or course choice, poor academic preparedness, difficulties with social integration and issues with adapting to university life relate to non-completion (Christie et al., 2004; Smith \& Naylor, 2001). There could be similarities in experiences, but research is needed to directly compare across the same measures in autistic and non-autistic people. Gurbuz et al. (2019) compared the experiences of current autistic students to non-autistic students and found greater social and academic challenges, as well as higher prevalence of thoughts about withdrawing in autistic students. We would argue that autistic people experience unique strengths and challenges in HE (Robertson \& Ne'eman, 2008) that contribute differentially to non-completion.

\section{Implications}

In terms of improving the transition to university to help avoid non-completion, past research has tried to establish what makes a successful transition for autistic people. In a systematic review, Nuske, Rillotta, Bellon and Richdale (2019) examined the transition across different levels. They describe 
how, at the individual level, autistic characteristics (e.g. social difficulties and need for routine) as well as mental health difficulties and disclosure contribute to the transition experience. At the microsystem level, family and educational professionals play a role in supporting the transition. Beyond this, they describe how at the exosystem and macrosytem levels policy and general attitudes towards the inclusion of autistic people in society influence the transition. A successful transition thus impinges on an individualised support and appropriate services and policies that enable educational equality for autistic people (Nuske et al., 2019).

One approach to achieve better transitions involves positive partnerships between schools and universities (Toor et al., 2016). Toor et al. (2016) describe how reliable, appropriately trained designated contacts during the transition period could help autistic people better navigate this process. Lei, Calley, Brosnan, Ashwin and Russell (2018) evaluated a transition programme for autistic young people considering applying to university. The programme gave a 'taste' of university life, covering academic, social and wellbeing aspects of university. The evaluation indicated positive outcomes in the short-term, such as reducing participant's concerns about university. Although the programme did not follow-up the participants or examine if they completed $\mathrm{HE}$, the positive findings suggest that this type of programme has potential efficacy in supporting the transition.

Social issues including feeling less included or part of the university community were also identified as a factor related to non-completion, and overall participants reported high levels of loneliness. Universities and student unions must consider how they can ensure that all students feel part of the university community. They must be proactive and accessible for all - for some, the social challenge will be with taking the first steps, therefore they may need support early on. This could be achieved through campus events beyond arrival week, clear information about societies and how to access them, and peer support whereby students in the years above are paired with new students. In this study, those who graduated discussed how they had social support from meeting like-minded people typically through structured activities and societies. A wide range of societies and ensuring these are accessible would be important, such as making sure activities are not centred around alcohol or in uncomfortable sensory environments.

Academic support could also be improved - for example with staff being more approachable and able to identify issues early to direct students to support. However, knowledge and understanding of 
autism in university staff is considered relatively poor (Knott \& Taylor, 2014), thus raising awareness in staff is important (Morris, 2011) as well as improving autism understanding (Beardon \& Edmonds, 2007). It is vital academic and support staff are appropriately trained to work with autistic students, especially to support students who are considering dropping out. Ideally, staff should have the skills to help students who are struggling but are undiagnosed. In the first few weeks of university, academic staff need to develop positive rapport with their students, especially within the role of tutor, so that their students feel comfortable disclosing when they are struggling and the tutor listens and directs the student to appropriate support.

Overall, the current study highlights how different factors may contribute to the risk of non-completion for autistic students, a previously neglected area of research. Finding the transition to university difficult may increase the risk of withdrawing from university, alongside social and academic challenges experienced during the degree. It is imperative that universities acknowledge the difficulties autistic students face early on in their degree, and endeavour to identify strategies to retain autistic students. Further, universities should consider how they could be more accessible in general, given that many autistic people may be undiagnosed at university. 


\section{Acknowledgements}

This study received financial support from the Department of Psychology at Royal Holloway. Thank you to the two autistic people who provided feedback early on in the conception of this study. Thank you to Louise Vinales and Rhoda Breakell for research assistance.

The authors have no conflict of interest to declare. 


\section{References}

Ackles, L., Fields, H., \& Skinner, R. (2013). A Collaborative Support Model for Students on the Autism Spectrum in College and University Housing. Journal of College and University Student Housing, 40(1), 200-212.

American Psychiatric Association (2013). Diagnostic and Statistical Manual of Mental Disorders (Fifth edition). Arlington, VA: American Psychiatric Publishing.

Anderson, A. H., Carter, M., \& Stephenson, J. (2018). Perspectives of university students with autism spectrum disorder. Journal of Autism and Developmental Disorders, 48(3), 651-665.

Barnhill, G. P. (2014). Supporting students with Asperger syndrome on college campuses. Focus Autism Other Developmental Disabilities, 31(1), 3-15.

Beardon, L., \& Edmonds, G. (2007). The needs of adults with Asperger syndrome compiled by ASPECT consultancy report: A national report on the needs of adults with Asperger syndrome. Retrieved June 28 from https://sheffield.ac.uk/polopoly fs/1.34791!/file/ASPECT Consultancy report.pdf

Bolourian, Y., Zeedyk, S. M., \& Blacher, J. (2018). Autism and the university experience: Narratives from students with neurodevelopmental disorders. Journal of Autism and Developmental Disorders, 48(10), 3330-3343.

Brosnan, M., \& Mills, E. (2016). The effect of diagnostic labels on the affective responses of college students towards peers with 'Asperger's Syndrome' and 'Autism Spectrum Disorder'. Autism, 20(4), 388-394.

Cai, R. Y., \& Richdale, A. L. (2016). Educational experiences and needs of higher education students with autism spectrum disorder. Journal of Autism and Developmental Disorders, 46(1), 31-41.

Chown, N., Baker-Rogers, J., Hughes, L., Cossburn, K. N., \& Byrne, P. (2018). The 'High Achievers' project: an assessment of the support for students with autism attending UK universities. Journal of Further and Higher Education, 42(6), 837-854. 
Christie, H., Munro, M., \& Fisher, T. (2004). Leaving university early: Exploring the differences between continuing and non-continuing students. Studies in Higher Education, 29(5), 617636.

Cox, B. E., Thompson, K., Anderson, A., Mintz, A., Locks, T., Morgan, L., ... \& Wolz, A. (2017). College experiences for students with autism spectrum disorder: Personal identity, public disclosure, and institutional support. Journal of College Student Development, 58(1), 71-87.

Cresswell, L., Hinch, R., \& Cage, E. (2019). The experiences of peer relationships amongst autistic adolescents: A systematic review of the qualitative evidence. Research in Autism Spectrum Disorders, 61, 45-60.

Duquette, C. (2000). Experiences at University: Perceptions of Students with Disabilities. Canadian Journal of Higher Education, 30(2), 123-41.

Eriksson, J. M., Andersen, L. M., \& Bejerot, S. (2013). RAADS-14 Screen: validity of a screening tool for autism spectrum disorder in an adult psychiatric population. Molecular Autism, 4(1), 49.

Gelbar, N. W., Reichow, B., \& Smith, I. (2014). Systematic review of articles describing experience and supports of individuals with autism enrolled in college and university programs. Journal of Autism and Developmental Disorders, 44, 2593-2601.

Gelbar, N. W., Shefcyk, A., \& Reichow, B. (2015). A comprehensive survey of current and former college students with autism spectrum disorders. The Yale Journal of Biology and Medicine, 88(1), 45.

Glennon, T.J. (2001). The stress of the university experience for students with Asperger syndrome. Work, 17, 183-190

Gobbo, K., \& Shmulsky, S. (2013). Faculty experience with college students with autism spectrum disorders. Focus on Autism and Other Developmental Disabilities, 29(1), 13-22.

Gurbuz, E. and Hanley, M. and Riby, D. M. (2019). University students with autism: the social and academic experiences of University in the UK, Journal of Autism and Developmental Disorders, 49 (2), 617-631. 
Harrison, N. (2006). The impact of negative experiences, dissatisfaction and attachment on first year undergraduate withdrawal. Journal of Further and Higher Education, 30(4), 377-391.

Higher Education Statistics Agency. Table 15- UK domiciled student enrolments by disability and sex 2014/15 to 2017/18. Retrieved June 26, 2019, from https://www.hesa.ac.uk/data-andanalysis/students/table-15.

Hsieh, H. F., \& S. E. Shannon (2005). Three Approaches to Qualitative Content Analysis. Qualitative Health Research, 15 (9), 1277-1288.

Hughes, M. E., Waite, L. J., Hawkley, L. C., \& Cacioppo, J. T. (2004). A short scale for measuring Ioneliness in large surveys: Results from two population-based studies. Research on Aging, 26(6), 655-672.

Jackson, S. L., Hart, L., Brown, J. T., \& Volkmar, F. R. (2018). Brief Report: Self-reported academic, social, and mental health experiences of post-secondary students with autism spectrum disorder. Journal of Autism and Developmental Disorders, 48(3), 643-650.

Jansen, D., Petry, K., Ceulemans, E., Noens, I., \& Baeyens, D. (2017). Functioning and participation problems of students with ASD in higher education: which reasonable accommodations are effective? European Journal of Special Needs Education, 32(1), 71-88.

Kenny, L., Hattersley, C., Molins, B., Buckley, C., Povey, C., \& Pellicano, E. (2015). Which terms should be used to describe autism? Perspectives from the UK autism community. Autism, 1362361315588200.

Knott, F., \& Taylor, A. (2014). Life at university with Asperger syndrome: A comparison of student and staff perspectives. International Journal of Inclusive Education, 18(4), 411-426.

Leedham, A., Thompson, A., Smith, R., \& Freeth, M. (2019). 'I was exhausted trying to figure it out': The experiences of females receiving an autism diagnosis in middle to late adulthood. Autism, 1362361319853442. 
Lei, J., Calley, S., Brosnan, M., Ashwin, C., \& Russell, A. (2018). Evaluation of a Transition to University Programme for Students with Autism Spectrum Disorder. Journal of Autism and Developmental Disorders, 1-15.

Lever, A. G., \& Geurts, H. M. (2016). Psychiatric co-occurring symptoms and disorders in young, middle-aged, and older adults with autism spectrum disorder. Journal of Autism and Developmental Disorders, 46(6), 1916-1930.

Longtin, S. E. (2014). Using the college infrastructure to support students on the autism spectrum. Journal of Postsecondary Education and Disability, 27(1), 63-72.

Loomes, R., Hull, L., \& Mandy, W. P. L. (2017). What is the male-to-female ratio in autism spectrum disorder? A systematic review and meta-analysis. Journal of the American Academy of Child \& Adolescent Psychiatry, 56(6), 466-474.

Luhmann, M., \& Hawkley, L. C. (2016). Age differences in loneliness from late adolescence to oldest old age. Developmental Psychology, 52(6), 943.

MacLeod, A., Allan, J., Lewis, A., \& Robertson, C. (2018). 'Here I come again': the cost of success for higher education students diagnosed with autism. International Journal of Inclusive Education, 22(6), 683-697.

Madriaga, M., \& Goodley, D. (2010). Moving beyond the minimum: Socially just pedagogies and Asperger's syndrome in UK higher education. International Journal of Inclusive Education, 14(2), 115-131.

Mazurek, M. O. (2014). Loneliness, friendship, and well-being in adults with autism spectrum disorders. Autism, 18(3), 223-232.

Morris, C. (2011). The aspect project: working together to enhance the learning experiences of students with Asperger syndrome at the University of Brighton. In G. Wisker, L. Marshall, N. Edmond \& S. Greener (Eds.), Partnerships: Articles from the learning and teaching conference 2010. (pp. 32-38) Brighton: University of Brighton Press. 
Nuske, A., Rillotta, F., Bellon, M., \& Richdale, A. (2019). Transition to higher education for students with autism: A systematic literature review. Journal of Diversity in Higher Education.

Robertson, S. M., \& Ne'eman, A. D. (2008). Autistic acceptance, the college campus, and technology: Growth of Neurodiversity in society and academia. Disability Studies Quarterly, 28(4).

Smith, J. P., \& Naylor, R. A. (2001). Dropping out of university: a statistical analysis of the probability of withdrawal for UK university students. Journal of the Royal Statistical Society: Series A (Statistics in Society), 164(2), 389-405.

Tennant, R ., Hiller, L., Fishwick, R., Platt, S., Joseph, S., Weich, S., ... \& Stewart-Brown, S. (2007). The Warwick-Edinburgh mental well-being scale (WEMWBS): development and UK validation. Health and Quality of Life Outcomes, 5(1), 63.

Thompson, C., Bölte, S., Falkmer, T., \& Girdler, S. (2018). Viewpoints on how students with autism can best navigate university. Scandinavian Journal of Occupational Therapy, 1-12.

Toor, N., Hanley, T., \& Hebron, J. (2016). The facilitators, obstacles and needs of individuals with autism spectrum conditions accessing further and higher education: A systematic review. Journal of Psychologists and Counsellors in Schools, 26, 166-190. http://dx.doi.org/10.1017/jgc.2016.21

Van Hees, V., Moyson, T., \& Roeyers, H. (2015). Higher education experiences of students with autism spectrum disorder: Challenges, benefits and support needs. Journal of Autism and Developmental Disorders, 45(6), 1673-1688.

Ward, D., \& Webster, A. (2018). Understanding the lived experiences of university students with autism spectrum disorder (ASD): A phenomenological study. International Journal of Disability, Development and Education, 65(4), 373-392.

White, S. W., Ollendick, T. H., \& Bray, B. C. (2011). College students on the autism spectrum: Prevalence and associated problems. Autism, 15(6), 683-701.

Wilkins, S., Butt, M. M., Kratochvil, D., \& Balakrishnan, M. S. (2016). The effects of social identification and organizational identification on student commitment, achievement and 
satisfaction in higher education. Studies in Higher Education, 41(12), 2232-2252.

https://doi.org/10.1080/03075079.2015.1034258

Wiorkowski, F. (2016). The qualitative report the experiences of students with autism spectrum disorders in college: A Heuristic exploration. The Qualitative Report, 20(6), 847-863.

Wolf, L. E. (2001). College students with ADHD and other hidden disabilities. Annals of the New York Academy of Sciences, 931(1), 385-395. 
Table 1. Top three reasons for choosing their university course, with percentage that selected that reason.

Graduated

Graduated after several Did not complete attempts

Top reasons for choosing the course
1. Interest in the subject $(86.8 \%)$

2. It was related to my career plans $(47.1 \%)$

3. Good reputation of the department (24.5\%)

Top reasons for choosing the university
1. Location - near to home $(50.3 \%)$

2. I made my decision more based on the course rather than the university (29.1\%)

3. The university's position in league tables (24.5\%) AND The university was based in a city/town with plenty to do in terms of culture e.g. museums, galleries, theatres $(24.5 \%)$
1. Interest in the subject 1. Interest in the subject (94.1\%) $(84.4 \%)$

2. It was related to my career plans $(47.1 \%)$

2. It was related to my career plans $(33.3 \%)$

3. The module or unit choices that were available $(29.4 \%)$

3. Good reputation of the department (24.4\%)

1. Location - near to home $(58.8 \%)$

1. Location - near to home $(44.4 \%)$

2. I made my decision more based on the course rather than the university $(26.5 \%)$ AND Going to that university would look good on my CV $(26.5 \%)$

2. I made my decision more based on the course rather than the university (24.4\%)

3. Location - far from home $(22.2 \%)$
3. The opportunities to meet new, potentially like-minded people (23.5\%) 
Table 2. Percentage of participants with different support needs met within each (A) completion group and (B) when they had received their autism diagnosis.

\begin{tabular}{|c|c|c|c|c|c|}
\hline & $\begin{array}{l}\text { I received support } \\
\text { for my needs as } \\
\text { an autistic } \\
\text { individual }\end{array}$ & $\begin{array}{l}\text { I received support } \\
\text { for my mental } \\
\text { health needs }\end{array}$ & $\begin{array}{l}\text { I received } \\
\text { support for my } \\
\text { physical health } \\
\text { needs }\end{array}$ & $\begin{array}{l}\text { I did not } \\
\text { receive any } \\
\text { support }\end{array}$ & $\begin{array}{l}\text { I asked for } \\
\text { support, but did } \\
\text { not receive it }\end{array}$ \\
\hline Graduated & $20.5 \%$ & $35.8 \%$ & $7.9 \%$ & & $7.9 \%$ \\
\hline $\begin{array}{l}\text { Graduated after several } \\
\text { attempts }\end{array}$ & $26.5 \%$ & $32.4 \%$ & $11.8 \%$ & $1 \%$ & $14.7 \%$ \\
\hline Did not complete & $24.4 \%$ & $24.4 \%$ & & $60.0 \%$ & $17.8 \%$ \\
\hline Chi-Square $p$ value & .63 & .37 & .25 & .37 & .13 \\
\hline Diagnosed before university & $64.1 \%$ & $51.3 \%$ & $7.7 \%$ & $15.4 \%$ & $15.4 \%$ \\
\hline Diagnosed during university & $60.6 \%$ & 5 & $12.1 \%$ & $27.3 \%$ & $21.2 \%$ \\
\hline Diagnosed after university & $4.4 \%$ & $24.1 \%$ & $6.6 \%$ & $66.4 \%$ & $8.0 \%$ \\
\hline Chi-Square $p$ value & .001 & .001 & .56 & .001 & .072 \\
\hline
\end{tabular}

Note. Participants could select more than one option, thus row totals greater than $100 \%$. 
Table 3. Categories identified by content analysis following the question "'what support would you have liked to have been provided [at university]?"

\begin{tabular}{|c|c|c|}
\hline Category & $\begin{array}{l}N \text { reporting category within } \\
\text { each group }\end{array}$ & Example quotes \\
\hline Academic support & $\begin{array}{l}\text { Did not complete }=10 \\
\text { Graduated }=28 \\
\text { Graduated }>1 \text { attempt }=6\end{array}$ & $\begin{array}{l}\text { "Individual dates for exams, more time in orals, } \\
\text { more help in organising myself when writing } \\
\text { essays..." }\end{array}$ \\
\hline Autism awareness & $\begin{array}{l}\text { Did not complete }=4 \\
\text { Graduated }=28 \\
\text { Graduated }>1 \text { attempt }=8\end{array}$ & $\begin{array}{l}\text { "As a late diagnosed adult, the most obviously } \\
\text { helpful thing would have been to have been } \\
\text { diagnosed earlier." }\end{array}$ \\
\hline & & $\begin{array}{l}\text { "I would have liked the lecturers to have been } \\
\text { educated on communication and meeting the needs } \\
\text { of an autistic person..." }\end{array}$ \\
\hline Counselling & $\begin{array}{l}\text { Did not complete }=5 \\
\text { Graduated }=23 \\
\text { Graduated }>1 \text { attempt }=6\end{array}$ & $\begin{array}{l}\text { "Someone I could trust to talk to about my } \\
\text { worries..." }\end{array}$ \\
\hline Staff support & $\begin{array}{l}\text { Did not complete }=5 \\
\text { Graduated }=0 \\
\text { Graduated }>1 \text { attempt }=0\end{array}$ & $\begin{array}{l}\text { "I felt as though the staff were unfriendly and } \\
\text { unsupportive, there was nowhere to go for support } \\
\text { or help" }\end{array}$ \\
\hline Sensory support & $\begin{array}{l}\text { Did not complete }=0 \\
\text { Graduated }=17 \\
\text { Graduated }>1 \text { attempt }=3\end{array}$ & $\begin{array}{l}\text { "A sensory room, including a quiet space where I } \\
\text { could go and stim, and with sensory friendly } \\
\text { equipment..." }\end{array}$ \\
\hline $\begin{array}{l}\text { Communication } \\
\text { support }\end{array}$ & $\begin{array}{l}\text { Did not complete }=0 \\
\text { Graduated }=13 \\
\text { Graduated }>1 \text { attempt }=4\end{array}$ & $\begin{array}{l}\text { "I would've liked to have someone give me } \\
\text { resources for how neurotypicals work and how to } \\
\text { approach tough conflicts..." }\end{array}$ \\
\hline $\begin{array}{l}\text { Networking } \\
\text { opportunities }\end{array}$ & $\begin{array}{l}\text { Did not complete }=0 \\
\text { Graduated }=5 \\
\text { Graduated }>1 \text { attempt }=0\end{array}$ & "A way to meet other Aspies" \\
\hline
\end{tabular}


Table 4. Categories extracted by content analysis from answers to the question "Would you like to tell us anything about your social experiences in university?"

\begin{tabular}{|c|c|c|}
\hline Category & $\begin{array}{l}N \text { reporting category within } \\
\text { each group }\end{array}$ & Example quotes \\
\hline $\begin{array}{l}\text { Limited or superficial } \\
\text { friendships }\end{array}$ & $\begin{array}{l}\text { Did not complete }=9 \\
\text { Graduated }=0 \\
\text { Graduated }>1 \text { attempt }=0\end{array}$ & $\begin{array}{l}\text { "I had some 'friends' but it was mostly superficial, } \\
\text { maybe saying hi when I saw them, maybe talking } \\
\text { briefly a few times, but nothing very meaningful." }\end{array}$ \\
\hline Loneliness & $\begin{array}{l}\text { Did not complete }=7 \\
\text { Graduated }=24 \\
\text { Graduated }>1 \text { attempt }=10\end{array}$ & $\begin{array}{l}\text { "I spent the vast majority of my time alone in my } \\
\text { room, and many weekends I went home to my } \\
\text { family so that I wouldn't be lonely... I was very } \\
\text { isolated and unhappy" }\end{array}$ \\
\hline Social difficulties & $\begin{array}{l}\text { Did not complete }=0 \\
\text { Graduated }=21 \\
\text { Graduated }>1 \text { attempt }=7\end{array}$ & $\begin{array}{l}\text { "I didn't know how to mix but desperately wanted to } \\
\text { fit in" }\end{array}$ \\
\hline Lack of acceptance & $\begin{array}{l}\text { Did not complete }=0 \\
\text { Graduated } n=17 \\
\text { Graduated }>1 \text { attempt }=0\end{array}$ & $\begin{array}{l}\text { "I felt isolated, misunderstood by academic staff, } \\
\text { rejected by peers" }\end{array}$ \\
\hline $\begin{array}{l}\text { Common and } \\
\text { structured interests }\end{array}$ & $\begin{array}{l}\text { Did not complete }=0 \\
\text { Graduated }=23 \\
\text { Graduated }>1 \text { attempt }=7\end{array}$ & $\begin{array}{l}\text { "Academic clubs related to my degree program } \\
\text { were a critical source of social engagement. Activity } \\
\text { clubs related to my interests were very helpful in } \\
\text { developing a sense of belonging and short- and } \\
\text { long-term friendships" }\end{array}$ \\
\hline $\begin{array}{l}\text { Overwhelmed by } \\
\text { student night-life }\end{array}$ & $\begin{array}{l}\text { Did not complete }=0 \\
\text { Graduated }=10 \\
\text { Graduated }>1 \text { attempt }=0\end{array}$ & $\begin{array}{l}\text { "...found this more difficult because most socializing } \\
\text { revolved around clubbing/alcohol which I wouldn't } \\
\text { be able to cope with" }\end{array}$ \\
\hline Distance & $\begin{array}{l}\text { Did not complete }=0 \\
\text { Graduated }=0 \\
\text { Graduated }>1 \text { attempt }=4\end{array}$ & $\begin{array}{l}\text { "I also didn't know how to make friends as most } \\
\text { people lived on campus and seemed to make } \\
\text { friends with people they lived with" }\end{array}$ \\
\hline
\end{tabular}


Table 5. Where participants lived in their first year of study.

\begin{tabular}{llll}
\hline & Graduated & $\begin{array}{l}\text { Graduated after } \\
\text { several attempts }\end{array}$ & Did not complete \\
\hline $\begin{array}{l}\text { Student halls/university } \\
\text { accommodation }\end{array}$ & $59.6 \%$ & $41.2 \%$ & $37.8 \%$ \\
Private house & $15.9 \%$ & $20.6 \%$ & $35.6 \%$ \\
Commuted from home & $24.5 \%$ & $32.4 \%$ & $24.4 \%$ \\
Other & - & $5.9 \%$ & $2.2 \%$ \\
\hline
\end{tabular}


Table 6. Logistic regression examining the predictors of completion in a matched sample of participants.

\begin{tabular}{|c|c|c|c|c|c|}
\hline & \multicolumn{5}{|c|}{ 95\% Confidence Intervals for Odds Ratio } \\
\hline & $B(\mathrm{SE})$ & Lower & Odds ratio & Upper & $p$ \\
\hline Social identification & $-.008(.080)$ & .85 & .99 & 1.16 & .92 \\
\hline $\begin{array}{l}\text { Organisational } \\
\text { identification }\end{array}$ & $-.17(.093)$ & .70 & .84 & 1.01 & .063 \\
\hline Transition ease & $.77(.26)$ & 1.31 & 2.17 & 3.59 & .003 \\
\hline Transition experience & $.82(.60)$ & .70 & 2.27 & 7.35 & .17 \\
\hline Academic experience & $-.058(.040)$ & .87 & .94 & 1.02 & .15 \\
\hline $\begin{array}{l}\text { Lived first year (private } \\
\text { vs. halls) }\end{array}$ & $-.91(.67)$ & .11 & .40 & 5 & .17 \\
\hline $\begin{array}{l}\text { Lived first year } \\
\text { (commute vs. halls) }\end{array}$ & $-.65(.68)$ & .14 & & 1.99 & .34 \\
\hline
\end{tabular}




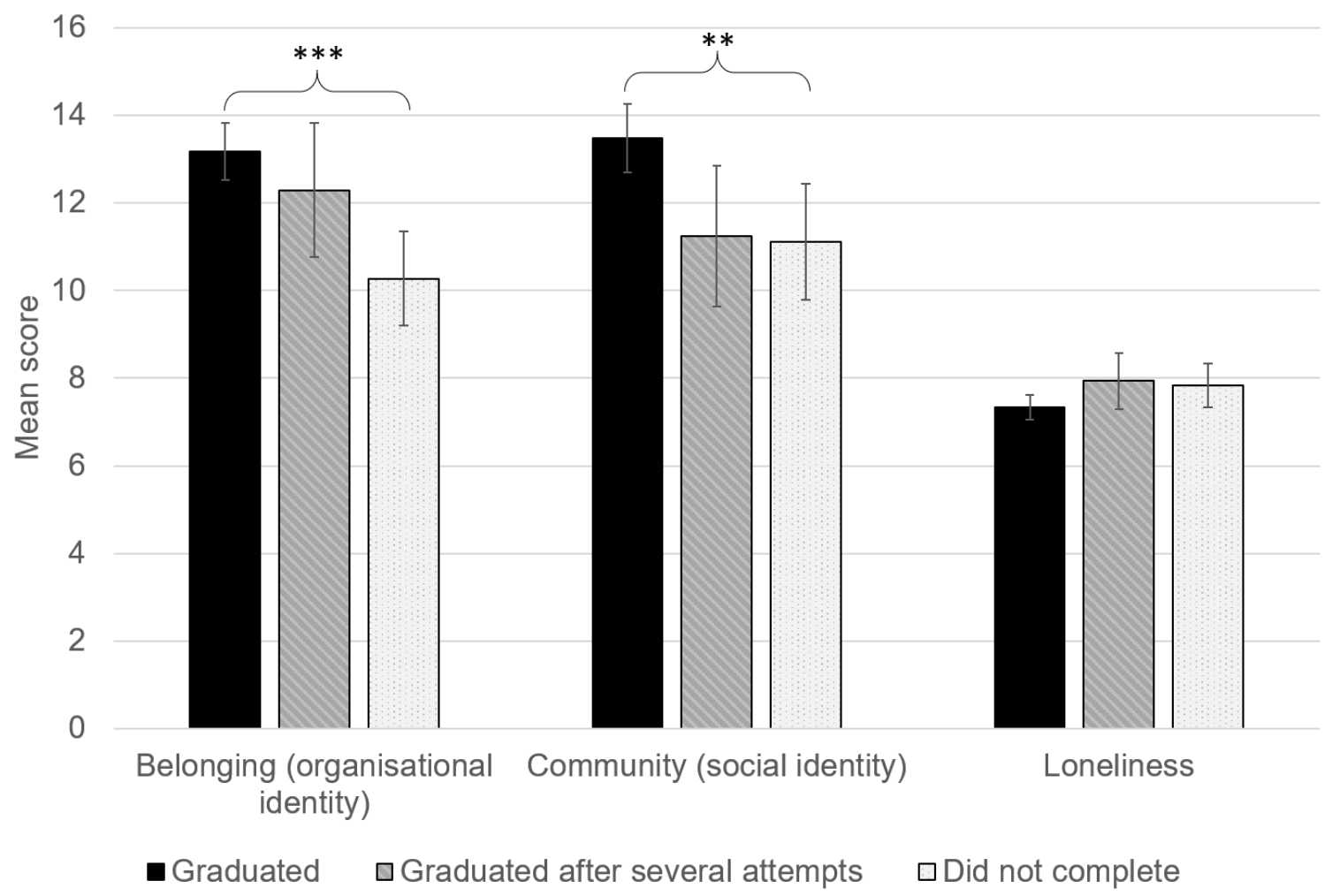

Figure 1. Feelings of organisational identification, social identification and loneliness within each group. ${ }^{* *} p<.001{ }^{* *} p=.007$ 